\title{
Blood Pressure and Lipid Lowering Effects of Nigella sativa Seeds and Honey Mixture
}

\author{
Sarina Mohamad, ${ }^{1,2}$ Nor Hayati Ibrahim, ${ }^{1} \& *$ HayatiMohd Yusof ${ }^{1}$ \\ ${ }^{1}$ School of Food Science and Technology, Universiti Malaysia Terengganu, Malaysia. ${ }^{2}$ Universiti Teknologi \\ MARA (Terengganu), Kuala Terengganu, Chendering 21080, Terengganu, Malaysia.
}

\begin{abstract}
The aim of this study was to investigate the effect(s) of a mixture ofNigella sativaseeds ( $N$. sativa; black cumin or fennel) and honey on (i) the modulation of cardiovascular disease (CVD) risks among hypercholesterolemic and healthy subjects; and (ii) to assess the lipid-soluble antioxidants capacity of samples using the photochemiluminescence (PCL) method. Sixty-five subjects, aged twenty-five to fifty-eight, were enrolledand assigned to three groups. Two groups of healthy andhypercholesterolemic subjects were supplemented with $\mathrm{N}$. sativa seeds and honey at $50 \mathrm{mg} / \mathrm{kg}$ (body weight) daily for three months. The third group served as control (healthy subjects without supplementation). Fasting blood samples were taken at baseline and again after three months of supplementation to measure (i) total cholesterol (TC), (ii) triglycerides (TG), (iii) low density lipoprotein-cholesterol (LDL-c), (iv) high density lipoprotein-cholesterol (HDL-c), (v) blood glucose, and (vi) hemoglobin concentrations. The findings were significant $(p<0.05)$, indicatingthat $N$. sativa seeds mixed with honey had hypolipidemic, antiobesity and hypotensive effects.Results showed significant reductions in TG (20.1\%), TC:HDL-c (12.3\%), accompanied by increased HDL-c (15.0\%) among healthy subjects.Supplementation also significantly decreased TC (6.2\%), TG (13.3\%), TC:HDL-c (19.5\%), with increased HDL-c (8.4\%) in the hypercholesterolemic group. Furthermore, there were significant reductions in body weight, body mass index and body fat by $2.3 \%, 2.2 \%, 4.5 \%$, and by $1.8 \%, 1.9 \%, 4.5 \%$ in healthy and hypercholesterolemic subjects, respectively. Blood pressureslowering werealso observed in hypercholesterolemic subjects with significant reductions in systolic blood pressure (3.9\%) and diastolic blood pressure (5.5\%). There were no significant effectsfromsupplementation on blood glucose or hemoglobin concentrations. It is postulated that the positive effects observed may be due to antioxidant activity. The combination of of $N$. sativa seeds with honey showed higher synergistic effectswhen compared withsupplementation of $N$. sativa seeds or honey on their own. Overall, these findings suggest that a mixture of $N$. sativa seeds with honey hasbeneficial effects in loweringthe citedrisk indicators for cardiovascular disease as a natural source of antioxidant activity; thus aidingthe maintainence of health bylowering CVD risk factors.
\end{abstract}

Keywords: lipid profile, antihypertensive, antiobesity, N.sativa seeds, honey, antioxidant activity

\section{Introduction}

CVD is an endemic and chronic human diseasethat over the past century has remained a common public health problem globally (Caterina et al. 2006). According to the World Health Organization (WHO, 2008), it is estimated that 17.1 million people died from CVD in 2004 and that this rate will increase to 23.4 million by 2030. Hence, CVD remains a leading cause of death in both developed and developing countries (Chia, 2011; WHO, 2011). By 2020 it isexpected to be the main cause of morbidity and mortality in most developing countries (Celermajer et al. 2012). In Malaysia, CVD incidence has increased rapidly in recent years (National Cardiovascular Disease, 2007), and is responsible for $17 \%$ of deaths in government hospitals nationwide (National Heart Association, 2011).

The use of natural supplements for disease management is both commonly practiced and gaining more attention. However, until now, there is adearth of systematically and scientifically ordered studieson the efficacy of dietary supplementation. The present study was initiated based on indications in Sura An-Nahl (The Bees), verse 69:

"...There comes forth from their bellies a drink of varying hues. Therein is a cure for men. Surely, in that is a Sign for people who reflect."

There is also a supporting hadith narrated by IbnuMajah, wherethe Prophet Muhammad (Peace Be Upon Him) said;

"Hold on to the use of the black seed, for it has the cure for every illness except death"(Mawsu'ah alHadith al-Syarif al-Kutub al-Sittah).

Previous studies have been carried out on the utilization of N. sativa seeds and honey because of empirically known beneficial impacts whichincludeCVD risk factors. The seeds of $\mathrm{N}$. sativa contain both fixed and volatile oils (Salem, 2005; Cheikh-Rouhou et al. 2007; Sultan et al. 2009). They are also rich sources of unsaturated fatty acids and quinones, especially thymoquinone (Butt \& Sultan, 2010; Lutterodt et al. 2010). N. 
sativa seeds have also been shown to improve blood lipid profiles in human studies (Bhatti et al. 2009; Tasawar et al. 2011; Mahmood et al. 2012; Sabzghabaee et al. 2012). Human studies on the therapeutic effects of N. sativa seeds havealso revealed hypoglycemic effects (Bamosa et al. 2010; Mohtashami et al. 2011); as well as hypotensive effects (Dehkordi \& Kamkhah, 2008); hematologic effects (Bamosa et al. 2010; Mohtashami et al. 2011); and antiobesity effects (Haque et al. 2011; Ghurbakhshani et al. 2012).

Similarly, other human studies have reported that honey possesses beneficial effects on CVD risk factors andthe blood lipid profile (Yaghoobi et al. 2008; Mushtaq et al. 2011); as well as on hemoglobin concentration (Al-Waili et al. 2006); and on body weight (Yaghoobi et al. 2008). However, up to the present, studies of honey's effects on blood glucose levels have been limited to animal trials (Fasanmade \&Alabi,2008; Sheriff et al. 2011); and on blood pressure (Oztasan \& Songur, 2007; Erejuwa et al.2012).

In most studies, favourable effects derived fromN. sativa seeds and honey have been reported separately. Only two studies have been done on their mixture and these were limited to healthy subjects.Moreover, the effectiveness of any intervention is more pronounced in secondary prevention settings (e.g., patients with high lipid profiles). No research has been attempted on the effects of a mixture ofN. sativa seeds and honey in hypercholesterolemic subjects as a secondary intervention. Therefore, it was anticipated that the present study would provide robust evidence in support of N.sativa seeds and honey in combination as a health supplement.Additionally, the present study is significantas it is the first to investigate the effects of $\mathrm{N}$. sativa seeds and honey in modulating risk factors for CVD as both primary andsecondary measures.

\section{Subjects Selection}

\section{Materials and Methods}

Sixty five male and female subjects were enrolled in this study. All subjects were provided with full disclosure via a subject information sheet. Inclusion criteriafor healthy subjects were as follows; twenty-five to fifty-eight years of age andno chronic diseases such as hypothyroidism, diabetes mellitus, gastrointestinal disorders, renal impairment or cardiac problems, not taking medications (lipid-lowering drugs, anti-diabetic, aspirin), not taking any dietary supplements, not vegetarian, not a vigorous exerciser (no more than three thirty minute vigorous sessions per week), not pregnant or lactating, not a heavy smoker $(<10$ cigarettes per day), not a blood donor for at least three months, not planning to lose weight,not participating in any clinical trial for the last three months. The sample size for this study was determined by using Altman's Normogram with the assumption that the effective size was 1.1 and the experiment had a test power of $98 \%$. This study was approved by the Universiti Malaysia Terengganu Committee of Research following the university's ethical standards for human trials.

\section{Study Design}

The study was conducted from May 2012 through October 2012. Alleligibile subjectsprovided a written informed consent form prior to intiating the trial, and each participantwas screened by a Health and Lifestyle Questionnaire. Baseline data for all participants was taken at the first visit. Subjects were categorized into three groups: (1) a control group ofhealthy subjects without supplementation $(\mathrm{n}=20)$; (2) a groupof healthy subjects supplemented with a paste mixture of $\mathrm{N}$. sativa seeds and honey $(\mathrm{n}=22)$; and (3)a hypercholesterolemic supplementation group at CVD risk (hypercholesterolemia, $n=23$ ), all of whom were supplemented with the paste mixture ofN. sativa seeds and honey. Subjects were required to consume the supplement daily according to the dosage as instructed for three months $(50 \mathrm{mg} / \mathrm{kg}$ of body weight). No placebo was used for the control group because it was too difficult to mimic the unique taste and aroma of the paste. During the supplemental period, subjectswere advised to maintain their usual daily lifestyles. Each participantwas followed-up minthly to remind them to consistently consume the paste as instructed.

\section{Data Collection and Measurements}

Height was measured using a portable stadiometer (SECA, Germany) and results were recorded to the nearest $0.5 \mathrm{~cm}$. Body weight was determined by using the Tanitadigital body fat monitor/scale model: UM- 026 (Tanita, UK), recorded to the nearest $0.1 \mathrm{~kg}$.Body fat percentage was determined by using the Tanitadigital body fat monitor/scale, model UM-026 (Tanita, UK), recorded to the nearest $0.1 \%$. Systolic blood pressure was measured from the left arm using an Omron Automatic Blood Pressure Monitor, HEM-7080,following the NICE Guideline (2011).

Blood collection was carried out in the morning after an overnight fasting of at least 10 hours. $40 \mu \mathrm{L}$ of whole blood was collected using a capillary blood collector to determine total cholesterol (TC), triglycerides (TG), high density lipoprotein-cholesterol (HDL-c), and low density lipoprotein-cholesterol (LDL-c) using Lipid Panel Test Strips with the auto CardioChek $\mathrm{P} \bullet \mathrm{A}^{\mathrm{TM}}$ Analyzer (Polymer Technology System, USA). Classification of the blood fasting lipid profile was based on the National Cholesterol Education Program Adult Treatment Panel III (NCEP, 2001).Fasting blood glucose level was determined by glucose reagent test strip with 
the Accu-Check Advantage Meter (Roche Diagnostics, Germany).Hemoglobin concentration was determined by using the HemoCue ${ }^{\circledR}$ B-Hemoglobin microcuvettesandHemoCue B-Hemoglobin Photometer (HemoCue AB, Sweden).

The final data was collected during the second visit during which subjects were required to return the remaining paste mixture, which was then weighedas a measure of compliance. Subjects who consumedless than $90 \%$ of the provided supplement were excluded from the final analysis. Of thesixty-five subjects recruited,data from sixty-onewas used for the final analysis. A summary of study design is shown in Figure 1.

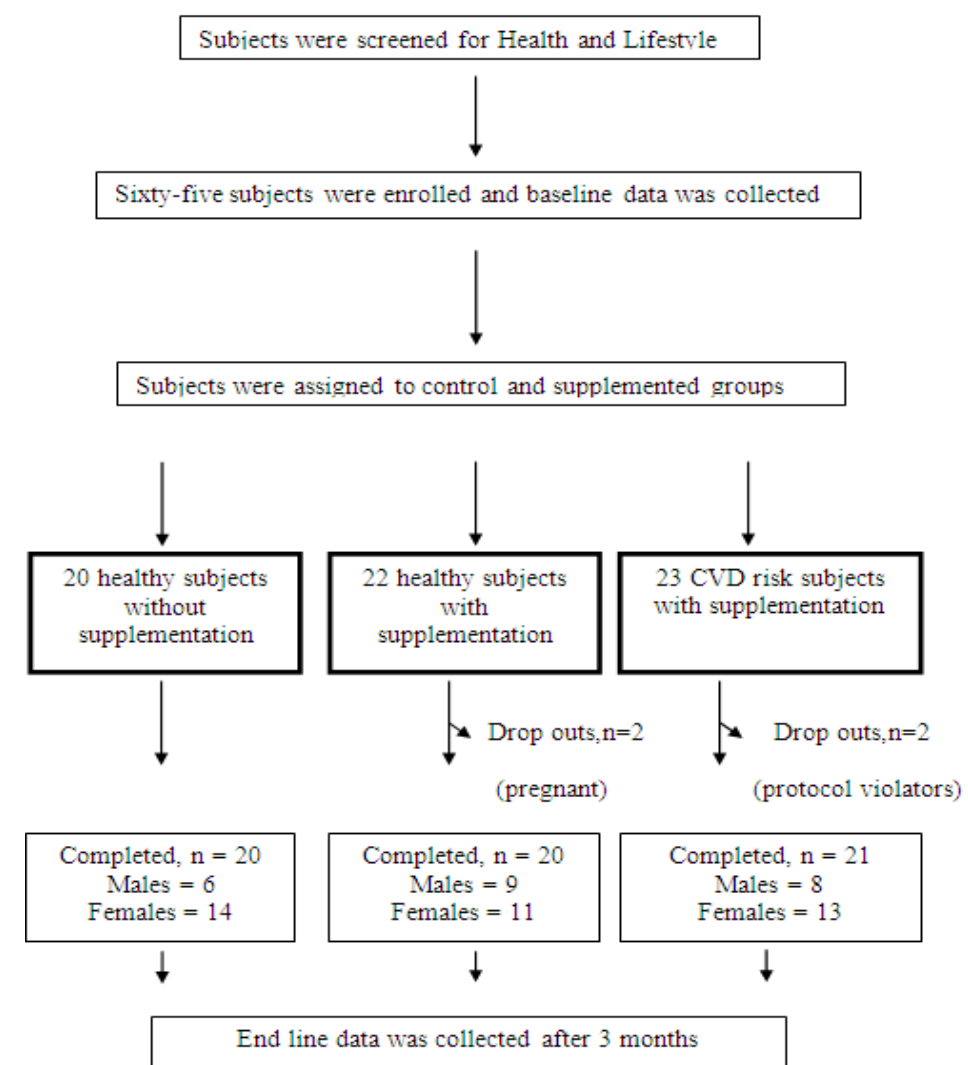

Figure 1: Study Design

The antioxidant capacity of lipid-soluble substances was assayed byluminol-photochemiluminescence according to the procedure used by Popov and Lewin (1999) asadapted to standard ACL protocol. Lipophilic antioxidants were measured withthePhotochem ${ }^{\circledR}$ instrument (Analytik Jena AG, Jena, Germany) using the antioxidant capacity, lipid-soluble substance (ACL) kit.

All data were statistically analyzed with SPSS software, version-18 (SPSS Inc., Chicago, IL). A paired sample t-test and variance analytics (one-way ANOVA) were applied. For variables where the criterion for normality was not met, corresponding non-parametric tests, as per the Wilcoxon Signed Rank and KruskalWallis tests, were utilized (Pallant, 2011). Data was presented witha mean (SD) or median $\left(10^{\text {th }}, 90^{\text {th }}\right.$ percentile). In all cases, the ' $\mathrm{P}$ ' value $\leq 0.05$ was taken to indicate a significant effect.

\section{Results and Discussion}

Table 1 show the baseline characteristics of the subjects according to groups. Based on the amount of returned N. sativa seeds and honey paste forthe supplemented groups, compliance was high, at $98.8 \%$. In addition, no adverse effectswere reported by participants. Table 2 showsthe effects of supplementation on the lipid profiles. These resultsrepresent the first reported effects of $\mathrm{N}$. sativa seeds mixed with honey as a supplementfor hypercholesterolemic subjects. Previous studies reported the effects of N. sativa seeds mixed with honey on lipid profiles observed in healthy subjects only (Yusof et al. 2012). Table 2 alsoshows changes in lipid profilesfor all three groups at the end of the study's intervention. 
Table 1:Baseline Characteristic of the Participants

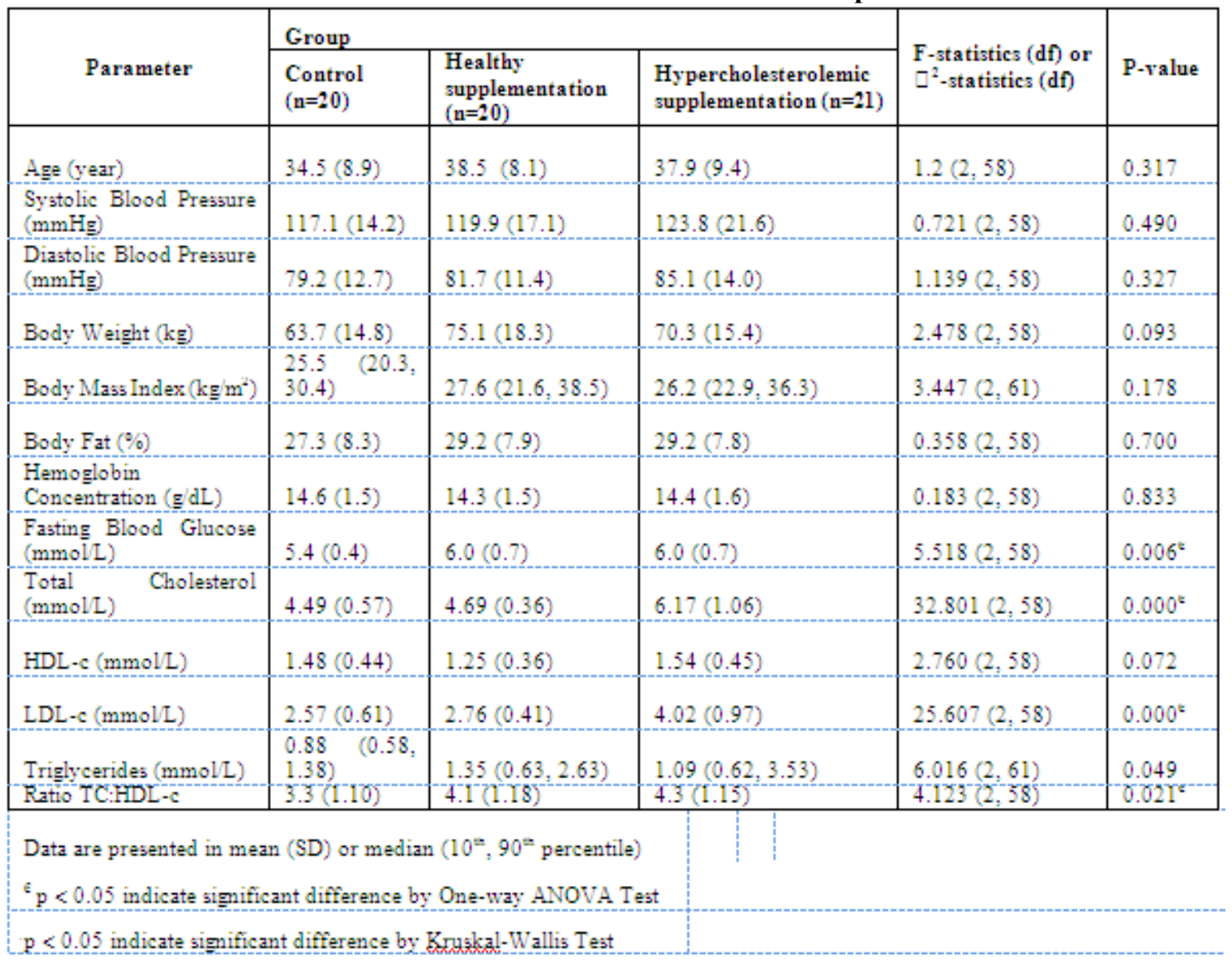

The present study found that theN. sativa seeds and honey mixture had pronounced effects on blood lipid profiles with significant overall reductions in TG by twenty percentand with significant elevations in HDLc by fifteen percent in healthy supplemented subjects. Ofgreater significancewas the supplement's beneficial effect onthe hypercholesterolemic group with anoverall reductionof TC by $6 \%$ and TG by $13.3 \%$; also reduced LDL-c by $6.7 \%$ (but not statistically significant), with a significant increase in HDL-c by $8.4 \%(\mathrm{p}<0.05)($ Table 2). Lipid lowering for both supplemented groups is possibly due to the effect of nigellamines contained in $\mathrm{N}$. sativa seeds (Tulukcu, 2011). In addition, it has been reported that fructooligosaccharides (FOS) in honey inhibitfatty acid synthesis in the liver, resulting in TG reduction (Nemoseck et al. 2011).

Table 2:Effects of Supplementation on Blood lipid and Blood Pressure

\begin{tabular}{|c|c|c|c|}
\hline Parameter/Trial Group & Control $(n=20)$ & $\begin{array}{l}\text { Healthy supplementation } \\
(\mathrm{n}=20)\end{array}$ & $\begin{array}{c}\text { Hypercholesterolemic } \\
\text { supplementation }(n=21)\end{array}$ \\
\hline $\begin{array}{l}\text { Total Cholesterol }(\mathrm{mmol} / \mathrm{L}) \\
\text { Baseline } \\
\text { Endline } \\
\text { Percent change }(\%)\end{array}$ & $\begin{array}{c}4.49(0.57) \\
4.77(0.71) \\
6.9^{\mathrm{a}}\end{array}$ & $\begin{array}{c}4.69(0.36) \\
4.66(0.58) \\
-0.04^{\mathrm{ab}}\end{array}$ & $\begin{array}{c}6.17(1.06) \\
5.73(0.71) \\
-6.2^{b}\end{array}$ \\
\hline $\begin{array}{l}\text { HDL-c }(\mathrm{mmol} / \mathrm{L}) \\
\text { Baseline } \\
\text { Endline } \\
\text { Percent change }(\%)\end{array}$ & $\begin{array}{c}1.48(0.44) \\
1.50^{\mathrm{a}}(0.42) \\
-2.5^{\mathrm{a}} \\
\end{array}$ & $\begin{array}{c}1.25(0.36) \\
1.41^{\mathrm{b}}(0.37) \\
15.0^{\mathrm{b}} \\
\end{array}$ & $\begin{array}{c}1.54(0.45) \\
1.79^{\mathrm{b}}(0.38) \\
8.4^{\mathrm{b}}\end{array}$ \\
\hline $\begin{array}{l}\text { LDL-c }(\mathrm{mmol} / \mathrm{L}) \\
\text { Baseline } \\
\text { Endline } \\
\text { Percent change }(\%)\end{array}$ & $\begin{array}{c}2.57(0.61) \\
2.85(0.77) \\
12.4^{\mathrm{a}} \\
\end{array}$ & $\begin{array}{c}2.76(0.41) \\
2.87(0.44) \\
4.7^{\mathrm{ab}}\end{array}$ & $\begin{array}{l}4.02(0.97) \\
3.66(0.68) \\
-6.7^{\mathrm{b}}\end{array}$ \\
\hline $\begin{array}{l}\text { Triglycerides }(\mathrm{mmol} / \mathrm{L}) \\
\text { Baseline } \\
\text { Endline } \\
\text { Percent change }(\%)\end{array}$ & $\begin{array}{l}0.88(0.58,1.38) \\
0.85(0.58,1.67) \\
-7.5\end{array}$ & $\begin{array}{l}1.35(0.63,2.63) \\
0.99(0.55,1.96) \\
-20.1\end{array}$ & $\begin{array}{l}1.09(0.62,3.53) \\
0.79(0.55,1.69) \\
-13.3\end{array}$ \\
\hline $\begin{array}{l}\text { Ratio TC: HDL-c } \\
\text { Baseline } \\
\text { Endline } \\
\text { Percent change (\%) }\end{array}$ & $\begin{array}{c}3.00(2.01,5.14) \\
3.25(2.20,5.39) \\
4.4^{\mathrm{a}}\end{array}$ & $\begin{array}{l}3.86(1.49) \\
3.50(0.77) \\
-12.3^{b}\end{array}$ & $\begin{array}{c}4.10(2.90,5.98) \\
3.10(2.62,5.26) \\
-19.5^{b}\end{array}$ \\
\hline $\begin{array}{l}\text { Systolic Blood Pressure }(\mathrm{mmHg}) \\
\text { Baseline }\end{array}$ & & & \\
\hline
\end{tabular}




\begin{tabular}{|l|c|c|c|}
\hline Endline & $117.1(14.24)$ & $119.9(17.12)$ & $123.8(21.62)$ \\
Percent change (\%) & $115.9(14.32)$ & $114.7(13.91)$ & -2.3 \\
& -0.9 & & -3.9 \\
\hline Diastolic Blood Pressure (mmHg) & & $81.7(11.44)$ & \\
Baseline & $79.2(12.68)$ & $78.3(9.60)$ & $85.1(14.03)$ \\
Endline & $76.5(11.90)$ & -1.2 & $79.9(12.09)$ \\
Percent change (\%) & -2.9 & -5.5 \\
\hline
\end{tabular}

Data are presented in mean (SD) or median $\left(10^{\text {th }}, 90^{\text {th }}\right.$ percentile) or indicate significant difference between baseline and endline in a column by Paired t-Test or Wilcoxon Signed Rank Test Values with different superscript letter indicates significant difference by One-way AOVA or

Howeverthe hypolipidemic effect of amixture of N. sativa seeds and honey on cholesterollowering activity are not fully understood. It is postulated that the effect is due to synergistic activity of the supplement's different constituents. In N. sativa seeds, the pharmacological actions of active constituents such as thymoquinone (TQ), sterols, flavonoids, soluble fiber and polyunsaturated fatty acids (PUFAs) (Butt \& Sultan, 2010; Lutterodt et al. 2010) have demonstrated important rolesin the reduction of plasma cholesterol. Moreover, the antioxidant components ofN. sativa seeds (fixed and essential oils)may inhibit lipid peroxidation (Sultan et al. 2009). Since the exact pathways of such activitiesare not yet well defined, the lipid-lowering activility of N. sativa seed might be due to a modulation of HMG-CoA reductase activity, as well as increased levels of LDL-receptors and the prevention of LDL-oxidation through antioxidant mechanisms (Ahmad \& Beg, 2013). It is also possible to reduce cholesterol levels through intestinal cholesterol absorption which is inhibited by plant sterols (Trautwein et al., 2003).

Honey has also demonstrated lipid-lowering activities that are likely due to antioxidanteffects on lipid metabolism (Nemoseck et al., 2011).In addition, honey was reported to have favorable effects on lowering TC and LDL-c while enhancing HDL-c levels (Chepulis \& Starkey, 2008). The antioxidant activity of honey has also been suggested as a beneficial adjunt influencing lipid metabolism (Nemoseck et al. 2011). Al-Waili (2004) observed the effects of $75 \mathrm{~g}$ of natural honey on hyperlipidemic patients for fifteen days and found that honey significantly reduced TC by eight percent and LDL-c by eleven percent. Yaghoobi et al. (2008) also found that honey reduced TC by $3.3 \%$, TG by $19 \%$, LDL-c by $4.3 \%$, while enhancing HDL-c production in obese patients after a month of supplemental treatment with $70 \mathrm{~g}$ of natural honey daily. These results are in accordance with Mushtaq et al. (2011), whose group obtained similar results (reduction of TC, TG, and LDL-c with increased HDL-c) in obese subjects after a month of supplementation with $40 \mathrm{~g}$ of honey dissolved in water with regular meals. To the contrary, Hussain et al. (2012) reported no significant effect in the lipid profile among healthy postmenopausal Malay women after four months of supplementation with Tualang honey at $20 \mathrm{~g} / \mathrm{day}$.

In terms of blood glucose and hemoglobin levels, results demonstrated nosignificant observablechangesconsistent with previous studieswhichreportedthat neitherN. sativa seed/extract nor honey had any significant effects oneither blood glucose levels (Sabzghabaee et al.2012; Hussain et al. 2012), or hemoglobin concentrations. Thus, the present resultsdid not exhibit hypoglycemic effects forN. sativa seed and honey mixture. This might be due to the fact that participants were not glucose intolerantor diabetic patients.

The present study demonstrated that theN.sativa seeds and honey mixture had a hypotensive effect in the hypercholesterolemic supplementation group but did not significantly affect blood pressure in healthy subjects (Table 2). The insignificant reduction of blood pressure in normotensive subjects ofthe healthy supplementation group agrees with Yusof et al. (2012) who also studied the effects of N. sativa seeds and honey mixture on the blood pressure of healthy individuals. No other studies of the effect of honey on blood pressure in humans has been previously reported.

Table 3 indicates that body weight and BMI increased and body fat was slightly decreased in the control group whencompared to baseline values, but were statistically not significant $(\mathrm{p}>0.05)$. The antiobesity effect of the N. sativa seed and honey mixture might be due to various components in the N. sativaseed, especially lipase which is responsible for antiobesity activity (Haque et al., 2011), but the exact mode of activity is not yet fully understood (Shah et al., 2012). Possible explanationsinclude the antioxidant activity of honey or its lower glycemic index in the regulation of body weight (Nemoseck et al., 2011). Nemoseck et al. (2011) reported that honey may havethe potential to suppress appetite which causes a reduction in food intake by increasing the production of serum leptin levels.

Table 3:Body Weight, BMI and Body Fat at Baseline and After Three Months Supplementation

\begin{tabular}{|l|c|c|c|}
\hline Parameter/Trial Group & Control (n=20) & $\begin{array}{c}\text { Healthy supplementation } \\
(\mathbf{n}=\mathbf{2 0})\end{array}$ & $\begin{array}{c}\text { Hypercholesterolemic } \\
\text { supplementation (n=21) }\end{array}$ \\
\hline Body Weight (kg) & $63.7(14.80)$ & $75.0(18.31)$ & $70.2(15.35)$ \\
Baseline & $64.0(15.64)$ & $72.1(17.58)$ & $68.9(15.18)$ \\
Endline & 0.17 & -2.26 & -1.83 \\
Percent change (\%) & & \\
\hline Body Mass Index $\left(\mathrm{kg} / \mathrm{m}^{2}\right)$ & & & \\
\hline
\end{tabular}




\begin{tabular}{|l|c|c|c|}
\hline Baseline & $25.0(4.64)$ & $27.6(21.6,38.5)$ & $26.2(22.9,36.3)$ \\
Endline & $25.1(4.86)$ & $26.4(21.1,37.2)$ & $25.6(23.1,35.5)$ \\
Percent change (\%) & 0.18 & -2.24 & -1.92 \\
\hline Body Fat (\%) & $27.32(8.26)$ & $29.2(7.88)$ & $29.2(7.82)$ \\
Baseline & $27.27(7.77)$ & $27.7(7.36)$ & $27.7(8.20)$ \\
Endline & 1.03 & -4.46 & -4.50 \\
Percent change (\%) & & \\
\hline
\end{tabular}

Data are presented in mean (SD) or median $\left(10^{\text {th }}, 90^{\text {th }}\right.$ percentile)

or indicate significant difference between baseline and endline in a column by Paired t-Test or Wilcoxon Signed Rank Test

The findings of the current study are also consistent with Yusof et al. (2012) whose group found that aN. sativa seeds and honey mixture produced an antiobesity effect. Results from this study showed greater weight loss (reduced body weight, BMI and body fat by $2.3 \%, 2.2 \%$ and $4.5 \%$, respectively in healthy subjects; and by $1.8 \%, 1.9 \%$ and $4.5 \%$, respectively in hypercholesterolemic subjects). It is possible that these results are due to the longer duration of the study and itslarger sample size.

Figure 2 indicates that the lipophilic antioxidant capacity of honey, N. sativa seeds, and a mixture of N. sativa seeds and honey as Trolox equivalents were $7.18(0.28), 9.67(0.19)$ and $29.94(0.75) \mu \mathrm{g} / \mathrm{mg}$, respectively. Interestingly, these resultsindicate that the mixture of $\mathrm{N}$. sativa seeds and honey demonstrated the highest antioxidant capacity. This finding suggests that lipid-soluble antioxidants in whole seeds of N. sativa have a synergistic effectwhen combined with antioxidants available in honey, thus causinga higher antioxidant capacity for the mixture as compared to eitherN. sativa seeds or honey alone. This result further suggests that consumption of theN. sativa seeds and honey mixture at lower dosage ( $50 \mathrm{mg} / \mathrm{kg}$ body weight), when compared to previous studies, exhibited positive effects on the modification of the lipid profile and CVD risk factors. Based on previous studies, consumption of N. sativaseeds or honey alone required higher dosages: $2-18.4$ g/day of N. sativa seeds (Sabzghabaee et al. 2012; Ghurbakhshani et al. 2012) and $40-80$ g/day of honey (AlWaili, 2004; Al-Waili et al. 2006; Mushtaq et al. 2011) in order to improve the lipid profile.

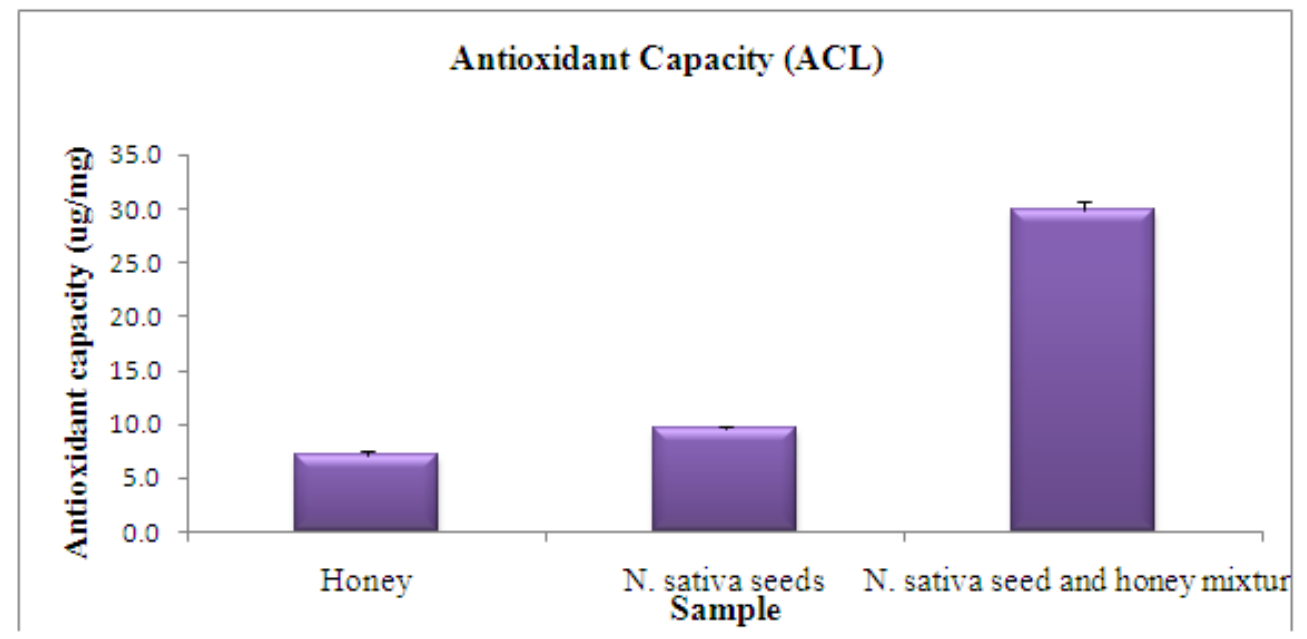

Figure 2: Lipid-soluble antioxidant capacity [Trolox equivalent $(\mu \mathrm{g} / \mathrm{mg})$ ] of $\mathrm{N}$. sativa seeds, honey and mixture of $\mathrm{N}$. sativa seeds and honeyassayed by photochemiluminescence (PCL-ACL)

A possible explanation for this result might be related to major bioactive constituents in the seeds of $\mathrm{N}$. sativa as fat-soluble antioxidant compounds (Salem, 2005; Cheikh-Rouhou et al. 2007; Sultan et al. 2009), with the assumption that it is rich in thymoquinone (TQ) as an oil extract (Butt \&Sultan, 2010; Lutterodt et al.,2010). TQ has been shown to exert an antioxidative effect (Ashraf et al. 2011) through inhibitingthe generation of the superoxide anion radical $\left(\mathrm{O}_{2}{ }^{\circ-}\right)$ (Mezeti et al. 2012). In addition, the natural antioxidant phenolics in honey can be classified into lipophilic or hydrophilic groups that probably contributed to antioxidative activityviathe reduction of lipid peroxidation (D'Arcy, 2005). Thus, it can be suggested that the variability of lipid-soluble antioxidant components in theN. sativa seeds and honey mixture may havedirectly modulated lipid profiles for subjects in this study. Lipid-soluble antioxidant compounds have been reported to have the capability to neutralize free radicals cell membrane fatsby inhibiting lipid peroxidation (Gupta \& Sharma, 2006). Hence, oxidation of LDL-c, by which the oxidized LDL-c both accumulates and is deposited on arterial walls, subsequently leadingto cardiovascular disease, can be avoided (Yashin et al., 2010).

Overrecent decades, studies have sucessfully focused on determining both the general and specific antioxidant activities of various extracts (Mohamed et al. 2010; Mezeti et al. 2012). Until now, no report has 
sufaced on the lipid-soluble antioxidant capacity of crude N. sativa seeds, of honey, or of the mixture of N. sativa seeds and honey. Thus, the current finding of the lipid-soluble antioxidant capacity ofN. sativa seeds, of honey, and ofa mixture of $\mathrm{N}$. sativa seeds and honey have been revealed for the first time byphotochemiluminescence (PCL-ACL) assay. The overall findings of the present study demonstrated that a mixture of $\mathrm{N}$. sativa seeds and honey has beneficial effects,not only as a nutritious health supplement, but also as a natural source of antioxidantsfor maintainenceofhealth by preventing or lowering risks for cardiovascular disease.

\section{Conclusion}

The present results demonstrate significant cardioprotective effects based on lipid profile modulation among hypercholesterolemic subjects when compared to healthy subjects. This clearly suggests that theN. sativa seeds and honey mixture has a positive effect on the management of CVD. This key finding calls for further research in which different dosages of the $\mathrm{N}$. sativa seeds and honey mixture may be utilized in order to identify optimal dosagesfor more effectiveand efficient lowering of the lipid profile in order to help reduce CVDmorbidity and mortality.

\section{References}

[1]. Ahmad, S., \& Beg, Z. H. (2013). Elucidation of mechanisms of actions of thymoquinone-enriched methanolic and volatile oil extracts from Nigella sativa against cardiovascular risk parameters in experimental hyperlipidemia. Lipids in Health and Disease, $12(86), 1-12$.

[2]. Al-Waili, N. S. (2004). Natural honey lowers plasma glucose, C-reactive protein, homocysteine and blood lipids in healthy, diabetic and hyperlipidemic subjects: comparison with dextrose and sucrose. Journal of Medicinal Food, 7(1), 100-107.

[3]. Al-Waili, N. S., Al-Waili, T. N., Al-Waili, A. N., \& Saloom, K. S. (2006). Influence of natural honey on biochemical and hematological variables in AIDS: a case study. Scientific World Journal, 2(6), 1985-1989.

[4]. Ashraf, S. S., Rao, M. V., Kaneez, F. S., Qadri, S., Al-Marzouqi, A. H., Chandranath, I. S., et al. (2011). Nigella sativa extract as a potent antioxidant for petrochemical-induced oxidative stress. Journal of Chromatographic Science, 49(4), $321-326$.

[5]. Bamosa, A. O., Kaatabi, H., Lebda, F. M., Elq, A.-M. A., \& Al-Sultan, A. (2010). Effect of Nigella sativa seeds on the glycemic control of patients with type 2 diabetes mellitus. Indian Journal of Physiology and Pharmacology, 54(4), 344-354.

[6]. Bhatti, I. U., Rehman, F. U., Khan, M. A., \& Marwat, S. K. (2009). Effect of prophetic medicine Kalonji (Nigella sativa L.) on lipid profile of human beings: an in vivo approach. World Applied Sciences Journal, 6(8), 1053-1057.

[7]. Butt, M. S., \& Sultan, M. T. (2010). Nigella sativa: reduces the risk of various Maladies. Critical Reviews in Food Science and Nutrition, 50(7), 654-665.

[8]. Caterina, R. D., Zampolli, A., Turco, S. D., Madonna, R., \& Massaro, M. (2006). Nutritional mechanisms that influence cardiovascular disease. American Journal of Clinical Nutrition, 83(suppl), 421S-426S.

[9]. Celermajer, D. S., Chow, C. K., Marijon, E., Anstey, N. M., \& Woo, K. S. (2012). Cardiovascular disease in the Developing World: Prevalences, patterns, and the potential of early disease detection. Journal of the American College of Cardiolohy., 60(14), 12071216.

[10]. Cheikh-Rouhou, S., Besbes, S., Hentati, B., Blecker, C., Deroanne, C., \& Attia, H. (2007). Nigella sativa L.: Chemical composition and physicochemical characteristics of lipid fraction. Food Chemistry, 101, 673-681.

[11]. Chepulis, L., \& Starkey, N. (2008). The long-term effects of feeding honey compared with sucrose and a sugar-free diet on weight gain, lipid profiles, and DEXA measurements in rats. Journal of Food Science, 73(1), H1-H7.

[12]. Chia, Y. C. (2011). Review of tools of cardiovascular risk stratification: interpretation, customisation and application in clinical practice. Singapore Medical Journal,52(2), 116-123.

[13]. D'Arcy, B. R. (2005). Antioxidants in Australian floral honeys - Identification of health-enhancing nutrient components. Kingston: Rural Industries Research and Development Corporation.

[14]. Dehkordi, F. R., \& Kamkhah, A. F. (2008). Antihypertensive effect of Nigella sativa seed extract in patients with mild hypertension. Fundamental \& Clinical Pharmacology, 22, 447-452.

[15]. Erejuwa, O. O., Sulaiman, S. A., Wahab, M. S., Sirajudeen, K. N., Salleh, S., \& Gurtu, S. (2012). Honey supplementation in spontaneously hypertensive rats elicits antihypertensive effect via amelioration of renal oxidative stress. Oxidative Medicine and Cellular Longevity, 1-14.

[16]. Fasanmade, A. A., \& Alabi, O. T. (2008). Differential effect of honey on selected variables in Alloxan-induced and fructoseinduced diabetic rats. African Journal of Biomedical Research, 11, 191-196.

[17]. Ghurbakhshani, A., Asghar, J., Bashir, Z., Chaudhry, A. M., Asif, S., \& Murad, S. (2012). Herbal medicine is effective for lowering serum lipids with least side effects. International Journal of Pharmaceutical Research and Development, 4(1), 140-144.

[18]. Gupta, V. K., \& Sharma, S. K. (2006). Plants as natural antioxidants. Natural Product Radiance, 5(4), 326-334.

[19]. Haque, S. F., Nasiruddin, M., \& Najmi, A. (2011). Indigenous herbal product Nigella sativa proved effective as an Anti-obesity therapy in metabolic syndrome. International Journal of Medicobiological Research, 1(3), 173-176.

[20]. Hussain, N. H., Sulaiman, S. A., Hassan, I. I., Kadir, A. A., Nor, N. M., Ismail, S. B., et al. (2012). Randomized controlled trial on the effects of Tualang honey and hormonal replacement therapy (HRT) on cardiovascular risk factors, hormonal profiles and bone density among postmenopausal women: a pilot study. Journal of Food Research, 1(2), 171-188.

[21]. Lutterodt, H., Luther, M., Slavin, M., Yin, J.-J., Parry, J., Gao, J.-M., et al. (2010). Fatty acid profile, thymoquinone content, oxidative stability, and antioxidant properties of cold-pressed black cumin seed oils. LWT - Food Science and Technology, 43, 1409-1413.

[22]. Mezeti, A., Mezeti, H., Boudiaf, K., Mustapha, B., \& Bouriche, H. (2012). Polyphenolic profile and antioxidant activities of Nigella sativa seed extracts in vitro and in vivo. World Academy of Science, Engineering and Technology, 64, 24-32.

[23]. Mohamed, D. A., Hamed, T. E., \& A-Okbi, S. Y. (2010). Reduction in hypercholesterolemia and risk of cardiovascular diseases by mixtures of plant food extracts: a study on plasma lipid profile, oxidative stress and testosterone in rats. Grasas Y Aceites, 61(4), 378-389.

[24]. Mohamed, M., Sirajudeen, K., Swamy, M., Yaacob, N.S., \&Sulaiman, S.A. (2010). Studies on the antioxidant properties of Tualang honey of Malaysia. African Journal of Traditional, Complementary and Alternative Medicines, 7(1), 59-63. 
[25]. Mohtashami, R., Amini, M., Huseini, H. F., Ghamarchehre, M., Sadeqhi, Z., Hajiagaee, R., et al. (2011). Blood glucose lowering effects of Nigella sativa L. seeds oil in healthy volunteers: a randomized, double-blind, placebo-controlled clinical trial. Journal of Medicinal Plants, 10(39), 90-94.

[26]. Mushtaq, R., Mushtaq, R., \& Khan, Z. T. (2011). Effects of natural honey on lipid profile and body weight in normal weight and obese adults: a randomized clinical trial. Pakistan Journal of Zoology, 43(1), 161-169.

[27]. Nemoseck, T. M., Carmody, E. G., Furchner-Evanson, A., Gleason, M., Li, A., Potter, H., et al. (2011). Honey promotes lower weight gain, adiposity, and triglycerides than sucrose in rats. Nutrition Research, 31, 55-60.

[28]. NICE Guideline. (2011). Hypertension: clinical management of primary hypertension in adults. http://www.nice.org.uk/guidance/CG34. Accessed on 7 August 2012.

[29]. Oztasan, N., \& Songur, A. (2007). The use of "Mad Honey" as an antihypertensive agent in rats - a preliminary study. The Medical Journal of Kocatepe, 8, 55-58.

[30]. Popov, I. N., \& Lewin, G. (1999). Photochemiluminescent detection of antiradical activity. VI. Antioxidant characteristics of human blood plasma, low density lipoprotein, serum albumin and amino acids during in vitro oxidation. Luminescence, 14, $169-174$.

[31]. Sabzghabaee, A. M., Dianatkhah, M., Sarrafzadegan, N., Asgary, S., \& Ghannadi, A. (2012). Clinical evaluation of Nigella sativa seeds for the treatment of hyperlipidemia: a randomized, placebo controlled clinical trial. Medical Archives, 66(3), 198-200.

[32]. Salem, M. L. (2005). Immunomodulatory and therapeutic properties of the Nigellasativa L. seed. International Immunopharmacology, 5, 1749-1770.

[33]. Shah, A. S., Khan, G. M., Badshah, A., Shah, S. U., Shah, K. U., Mirza, S. A., et al. (2012). Nigella sativa provides protection against metabolic syndrome. African Journal of Biotechnology, 11(48), 10919-10925.

[34]. Sheriff, M., Tukur, M. A., Bilkisu, M., Sera, S., \& Falmata, A. (2011). The effect of oral administration of honey and glucophage alone or their combination on the serum biochemical parameters of induced diabetic rats. Research in Pharmaceutical Biotechnology, 3(9), 118-122.

[35]. Sultan, M. T., Butt, M. S., Anjum, F. M., Jamil, A., Akhtar, S., \& Nasir, M. (2009). Nutritional profile of indigenous cultivar of black cumin seeds and antioxidant potential of its fixed and essential oil. Pakistan Journal of Botany, 41(3), 1321-1330.

[36]. Tasawar, Z., Siraj, Z., Ahmad, N., \& Lashari, M. H. (2011). The effects of Nigella sativa (Kalonji) on lipid profile in patients with stable coronary artery disease in Multan, Pakistan. Pakistan Journal of Nutrition, 10 (2), 162-167.

[37]. Trautwein, E. A., Duchateau, G. S., Lin, Y., Mel'nikov, S. M., Molhuizen, H. O., \& Ntanios, F. Y. (2003). Proposed mechanisms of cholesterol-lowering action of plant sterols. European Journal of Lipid Science and Technology, 105(3-4), 171-185.

[38]. Tulukcu, E. (2011). A comparative study on fatty acid composition of black cumin obtained from different regions of Turkey, Iran and Syria. African Journal of Agricultural Research, 6(4), 892-895.

[39]. World Health Organization.(2008). World health statistics $2008 . \quad$ Geneva: http://www.who.int/gho/publications/world health statistics/ENWHS08 Full.pdf. Accessed on 2 September 2012.

[40]. World Health Organization.(2011). Haemoglobin concentrations for the diagnosis of anaemia and assessment of severity.Vitamin and Mineral Nutrition Information System. Geneva, World Health Organization, 2011. http://www.who.int/vmnis/indicators/haemoglobin.pdf. Accessed on 15 September 2012.

[41]. Yaghoobi, N., Al-Waili, N., Ghayour-Mobarhan, M., Parizadeh, S., Abasalti, Z., Yaghoobi, Z., et al. (2008). Natural honey and cardiovascular risk factor; effects on blood glucose, cholesterol, triacylglycerole, CRP, and body weight compared with sucrose. The Scientific World Journal, 8, 463-469.

[42]. Yashin, Y. I., Nemzer, B. V., Ryzhnev, V. Y., Yashin, A. Y., Chernousova, N. I., \& Fedina, P. A. (2010). Creation of a databa nk for content of antioxidants in food products by an amperometric method. Molecules, 15, 7450-7466.

[43]. Yusof, H. M., Ling, L. P., Muhamad, S., \&Suhaimin, N. (2012).Effect of Nigella sativa and honey mixture (NSxH) on cardiovascular risk factors in healthy adults. $11^{\mathrm{TH}}$ International Annual Symposium on Sustainability Science and Management 2012 (pp. 703-712). Kuala Terengganu, Malaysia: Universiti Malaysia Terengganu.

[44]. Yusuf 'Ali, A. (1938). The Holy Quran Translation and Commentary (3 ${ }^{\text {rd }}$ ed.). Lahore: National Print Press 